\title{
Previous Preterm Birth and Current Maternal Complications as a Risk Factor of Subsequent Stillbirth
}

\author{
Boubakari Ibrahimou, ${ }^{1}$ Cynthia Anozie, ${ }^{2}$ Cara de la Cruz, ${ }^{3}$ and Hamisu Salihu ${ }^{4}$ \\ ${ }^{1}$ Department of Biostatistics, Robert Stempel College of Public Health \& Social Work, Florida International University, \\ 11200 SW 8th Street, AHC2 576A, Miami, FL 33199, USA \\ ${ }^{2}$ Department of Public Health, College of Health and Human Services, Western Kentucky University, \\ 1906 College Heights Boulevard, Bowling Green, KY 42101, USA \\ ${ }^{3}$ Department of Epidemiology \& Biostatistics, College of Public Health, University of South Florida, Tampa, FL 33012, USA \\ ${ }^{4}$ Department of Family and Community Medicine, Baylor College of Medicine, 3701 Kirby Drive, Suite 600, Houston, TX 77098, USA
}

Correspondence should be addressed to Boubakari Ibrahimou; bibrahim@fiu.edu

Received 29 April 2015; Revised 8 July 2015; Accepted 15 July 2015

Academic Editor: Peter N. Lee

Copyright ( $) 2015$ Boubakari Ibrahimou et al. This is an open access article distributed under the Creative Commons Attribution License, which permits unrestricted use, distribution, and reproduction in any medium, provided the original work is properly cited.

Purpose. To examine the association between previous preterm birth and the risk of stillbirth. Methods. This population-based retrospective cohort study analyzed live births and stillbirth records in Missouri (1989-1997). The main outcome of interest was stillbirth occurrence while the exposures were prior preterm birth. Adjusted odds ratios and $95 \%$ confidence intervals were computed using logistic regression. Results. Women who had a previous preterm birth have $63 \%$ increased odds of stillbirth in singleton pregnancies and $75 \%$ increased odds in twins as compared to those who did not have a preterm birth in a prior pregnancy $(\mathrm{AOR}=1.63,95 \% \mathrm{CI}=1.41-1.88$ and $\mathrm{AOR}=1.75,95 \% \mathrm{CI}=1.20-2.56)$, respectively. The most significant risk factor for stillbirth in singleton pregnancies was uterine bleeding $(\mathrm{AOR}=5.89,95 \% \mathrm{CI}=5.13-6.76)$. In twin pregnancies, it was the condition hydramnios/oligohydramnios $(\mathrm{AOR}=4.72,95 \% \mathrm{CI}=3.70-6.02)$. Eclampsia was associated with a heightened risk of stillbirth in singletons $(\mathrm{AOR}=2.45,95 \% \mathrm{CI}=1.41-4.12)$, but not in twins $(\mathrm{AOR}=0.96,95 \% \mathrm{CI}=0.13-7.00)$. Black mothers were more likely than white to experience stillbirth $(\mathrm{AOR}=2.10,95 \% \mathrm{CI}=1.99-2.22$ for singletons and $\mathrm{AOR}=1.51,95 \% \mathrm{CI}=1.27-1.79$ for twins). Conclusion. Stillbirth is a vital public health issue and its etiology is not well understood. Previous history of preterm birth was found to be associated with future stillbirth. Targeted early medical and obstetric care and interventions among women with preterm birth history may potentially reduce the likelihood of stillbirth.

\section{Introduction}

Stillbirth (defined as fetal death at 20 or more weeks of gestation) affects one in 160 births in the United States [1], with a global estimate of 3.2 million stillbirths annually [2], half of which occur before 28 weeks of gestation [3]. With the introduction of interventions for preeclampsia, $\mathrm{Rh}$ isoimmunization, and diabetes, the stillbirth rate has declined since the 1950s [4]. However, racial disparities in stillbirth rates persist [5-7], as rates among blacks are almost twice that of whites $[4,6]$. Since 2003, the stillbirth rate has remained at about 26,000 stillbirths each year [8].

Factors previously associated with increased risk for stillbirth include adolescent or advanced maternal age $[4,5,9]$, low socioeconomic status [9], low birth weight, lack of prenatal care [10,11], prenatal smoking [12], stillbirth in first pregnancy [13], preeclampsia, gestational diabetes, eclampsia [10], placental abruption, nulliparity, and smoking [14]. Other known risk factors for stillbirth are delayed and obstructed labor, maternal infections, hypertensive disorders that occur during pregnancy $[15,16]$, and anemia $[10,17]$. Prior research has revealed that the risk of stillbirth increases as gestational age progresses towards 42 weeks, with most occurring at 4142 weeks $[4,9,18,19]$. An in-depth report on preterm birth and stillbirth has been established [20].

Adverse pregnancy events in a prior pregnancy have been associated with negative outcomes in subsequent 
pregnancies. For example, women with three or more previous spontaneous abortions in previous pregnancies have been shown to be at a higher risk for preterm birth in subsequent pregnancies [21]. Obstetric interventions aimed at increasing preterm gestation and infant size can play a role in preventing stillbirth, as well as infant morbidity and mortality [22]. Studies in Sweden and the US have indicated an association between previous preterm and small for gestational age births and the subsequent risk of stillbirth $[23,24]$. They suggested that more studies are needed to confirm their findings.

This study aims to estimate the subsequent risk of stillbirth occurrence among mothers who experienced previous preterm birth and other risk factors using a large US population data. We further computed estimates to determine stillbirth risks associated with various maternal risk factors and pregnancy complications. Approximations that assessed the differences in stillbirth rates by maternal sociodemographic characteristics, including age, race, and educational level, were also calculated.

\section{Methods}

We conducted a population-based retrospective cohort study utilizing the Missouri maternally linked cohort data files for births between 1989 and 1997. The data file was collected by the Missouri Department of Health and Senior Services and contains individual records of live births and fetal deaths. Infants were linked with their biological mothers by the use of unique identifiers and were also verified to be from the second maternal pregnancy.

In this study, the exposure of interest was preterm birth (PTB) in previous pregnancies, while the outcome was stillbirth in the current pregnancy. PTB was defined as birth at less than 37 weeks of gestational age. Gestational age was calculated from the date of last normal menses minus the date of birth, in weeks. Stillbirth was defined to include both intrapartum (deaths during labor) and antepartum (deaths before labor onset) [25].

We examined maternal sociodemographic and risk factors in relation to PTB. Maternal medical risk factors were defined as any maternal health condition that could potentially be incompatible with fetal life or could cause fetal death. For this study, the maternal medical risk factors of interest included a range of pregnancy and labor complications, including uterine bleeding, eclampsia, preeclampsia, placenta previa, placental abruption, chronic hypertension, insulin-dependent diabetes and other forms of diabetes, acute/chronic lung disease, genital herpes, hydramnios/oligohydramnios, renal disease, and anemia. Demographic factors considered as likely confounders in the analysis included marital status, maternal age, prenatal smoking, number of fetuses born, maternal educational level, and maternal race. Maternal age was categorized as less than 18 years, 18 to 35 years, and above 35 years. Maternal education was classified into two groups: less than 12 years of education and 12 years or more of education. All maternal risk factors and demographic factors were based on data collected at the time of the second pregnancy.
Differences in sociodemographic characteristics by exposure status were assessed through bivariate analysis using chisquare tests. The rate of pregnancy and labor complications during the study period was computed by dividing the total number of cases by the total number of births and then multiplying by 1,000 . We conducted multivariable analysis with logistic regression to compute estimates of the $95 \%$ confidence intervals and odd ratios for the likelihood of stillbirth occurrence. Analyses were conducted with the $\mathrm{R}$ statistical package (version 2.15.2), and all hypothesis testing was carried out with a type 1 error rate set at 5\%. This study was approved by the institutional review board at the University of South Florida.

\section{Results}

Our study population consisted of 17,937 (1.40\%) mothers who experienced preterm birth in the first pregnancy, while the remaining carried their pregnancies to term. Live births totaled $1,268,138(99.31 \%)$ of the study population, while stillbirth comprised $8,780(0.69 \%)$ of all births. We selected viable births (20-44 weeks of gestation) that include 1,234,951 (96.71\%) singletons and 41,967 (3.29\%) twins.

Sociodemographic characteristics of the population under study at the time of the second pregnancy are represented in Table 1. Significant differences were observed in age, race, infant sex, maternal education level, paternal education level, marital status, prenatal smoking status, and parity among mothers who experienced stillbirth, as compared to those with a live birth $(p<0.0001)$. Mothers who experienced stillbirth were more likely to be black, unmarried, smokers, and of adolescent ( $<18$ years) or advanced age ( $>35$ years) with less than 12 years of education. Additionally, multiple gestation pregnancies were more common among women who experienced stillbirth.

The pregnancy and labor complication rates (per 1,000 births) experienced in the population during the second pregnancy are described in Table 2. Apart from maternal lung disease and preeclampsia, which showed no statistically significant difference among mothers, all other rates were higher for women who experienced stillbirths, as compared to those with live births, with the exception of genital herpes and other forms of diabetes mellitus. The most elevated rate among mothers with live births was observed for other forms of diabetes mellitus $(17.37 / 1000, p=0.005)$ while the highest rate amongst mothers with stillbirths was observed for placenta abruption $(75.74 / 1000, p<0.0001)$.

Adjusted odds ratios and 95\% confidence intervals from logistic regression analysis are presented in Table 3. Previous preterm birth was associated with $63 \%$ increased odds of stillbirth, as compared to live birth among singletons (AOR $=1.63,95 \% \mathrm{CI}=1.41-1.88)$ and $75 \%$ increased odds of stillbirth among twins (AOR $=1.75,95 \% \mathrm{CI}=1.20-2.56)$. Furthermore, pregnancy and labor conditions for the second pregnancy, including hydramnios/oligohydramnios, chronic hypertension, and uterine bleeding, were associated with increased odds of stillbirth occurrence in both groups, while eclampsia and insulin-dependent diabetes are associated with increased odds among singletons and reduced odds in twins 
TABLE 1: Sociodemographic characteristics of study population at the time of the second pregnancy.

\begin{tabular}{|c|c|c|c|}
\hline & $\begin{array}{c}\text { Stillbirth }^{\mathrm{a}} \\
n(\%)\end{array}$ & $\begin{array}{c}\text { Live birth }^{\mathrm{a}} \\
n(\%)\end{array}$ & $p$ value $^{\mathrm{b}}$ \\
\hline Maternal age & & & $<0.0001$ \\
\hline Less than 18 years & $532(6.11)$ & $52064(4.15)$ & \\
\hline 18 to 35 years & $7278(83.59)$ & $1115315(88.85)$ & \\
\hline Above 35 years & $897(10.30)$ & $87917(7.00)$ & \\
\hline Maternal race & & & $<0.0001$ \\
\hline White & $6220(71.91)$ & $1041145(84.44)$ & \\
\hline Black & $2429(28.08)$ & $191852(15.56)$ & \\
\hline Infant sex & & & $<0.0001$ \\
\hline Male & $4798(53.09)$ & $662673(51.22)$ & \\
\hline Female & $4239(46.91)$ & $631160(48.78)$ & \\
\hline Maternal educational level & & & $<0.0001$ \\
\hline Less than 12 years & $2040(25.10)$ & $247616(19.87)$ & \\
\hline 12 years or more & $6086(74.90)$ & $998390(80.13)$ & \\
\hline Paternal educational level & & & $<0.0001$ \\
\hline Less than 12 years & $882(16.05)$ & $135495(13.37)$ & \\
\hline 12 years or more & $4613(83.95)$ & $877774(86.63)$ & \\
\hline Marital status & & & $<0.0001$ \\
\hline Married & $5361(61.23)$ & $901026(71.80)$ & \\
\hline Not married & $3395(38.77)$ & $353932(28.20)$ & \\
\hline Maternal prenatal smoking & & & $<0.0001$ \\
\hline Yes & $2536(30.18)$ & $283699(22.69)$ & \\
\hline No & $5867(69.82)$ & 966767 (77.31) & \\
\hline Number of fetuses & & & $<0.0001$ \\
\hline Singleton & $7944(90.48)$ & 1227007 (96.76) & \\
\hline Twins & $836(9.52)$ & $41131(3.24)$ & \\
\hline
\end{tabular}

${ }^{a}$ Columns do not total due to missing data.

${ }^{\mathrm{b}}$ Significant $p$ values are in bold font. $p$ values of 0.05 or less were considered significant.

TABLE 2: Rates of pregnancy and labor complications experienced during the second pregnancy within the study population.

\begin{tabular}{|c|c|c|c|}
\hline Rates expressed per 1,000 & $\begin{array}{c}\text { Stillbirth } \\
n(\% o)\end{array}$ & $\begin{array}{c}\text { Live birth } \\
n(\%)\end{array}$ & $p$ value $^{\mathrm{a}}$ \\
\hline Previous preterm & $34094(26.70)$ & $18031(14.12)$ & $<0.0001$ \\
\hline Uterine bleeding & $39483(30.92)$ & $6679(5.23)$ & $<0.0001$ \\
\hline Eclampsia & $2184(1.71)$ & $894(0.70)$ & $<0.0001$ \\
\hline Placenta previa & $8160(6.39)$ & $3908(3.06)$ & $<0.0001$ \\
\hline Placenta abruption & $96714(75.74)$ & $8186(6.41)$ & $<0.0001$ \\
\hline Chronic hypertension & $20840(16.32)$ & $8939(7.00)$ & $<0.0001$ \\
\hline Other forms of diabetes & $17200(13.47)$ & $22181(17.37)$ & 0.005 \\
\hline Insulin-dependent diabetes & $13702(10.73)$ & $6896(5.40)$ & $<0.0001$ \\
\hline Preeclampsia & $43569(34.12)$ & $43071(33.73)$ & 0.840 \\
\hline Acute/chronic lung disease & $10931(8.56)$ & $9296(7.28)$ & 0.160 \\
\hline Genital herpes & $5976(4.68)$ & $9616(7.53)$ & 0.002 \\
\hline Hydramnios/oligohydramnios & $50273(39.37)$ & $16025(12.55)$ & $<0.0001$ \\
\hline Renal disease & $4955(3.88)$ & $2503(1.96)$ & $<0.0001$ \\
\hline Anemia & $24926(19.52)$ & $16013(12.54)$ & $<0.0001$ \\
\hline
\end{tabular}

${ }^{\text {a }}$ Significant $p$ values are in bold font. $p$ values of 0.05 or less were considered significant. 
TABLE 3: Adjusted odd ratios from logistic regression analysis for prediction of stillbirth by maternal risk factors.

\begin{tabular}{|c|c|c|}
\hline Predictor variables & $\begin{array}{c}\text { OR }(95 \% \mathrm{CI})^{\mathrm{b}} \\
\text { Singletons }\end{array}$ & $\begin{array}{c}\text { OR }(95 \% \mathrm{CI})^{\mathrm{b}} \\
\text { Twins } \\
\end{array}$ \\
\hline Previous preterm & $1.63(1.41-1.88)$ & $1.75(1.20-2.56)$ \\
\hline No previous preterm & 1.00 & 1.00 \\
\hline Eclampsia present & $2.45(1.41-4.25)$ & $0.96(0.13-7.00)$ \\
\hline Eclampsia absent & 1.00 & 1.00 \\
\hline Insulin-dependent diabetes & $1.74(1.38-2.19)$ & $0.67(0.27-1.63)$ \\
\hline No insulin & 1.00 & 1.00 \\
\hline Hydramnios/oligohydramnios & $2.28(1.99-2.62)$ & $4.72(3.70-6.02)$ \\
\hline No hydramnios & 1.00 & 1.00 \\
\hline Chronic hypertension & $2.04(1.70-2.45)$ & $1.25(0.70-2.25)$ \\
\hline No chronic hypertension & 1.00 & 1.00 \\
\hline Uterine bleeding & $5.89(5.13-6.76)$ & $4.19(2.75-6.38)$ \\
\hline No uterine bleeding & 1.00 & 1.00 \\
\hline Black & $2.10(1.99-2.22)$ & $1.51(1.27-1.79)$ \\
\hline White & 1.00 & 1.00 \\
\hline No smoking & $0.64(0.61-0.68)$ & $1.01(0.83-1.22)$ \\
\hline Smoking & 1.00 & 1.00 \\
\hline Maternal education level $<12$ years & 1.00 & 1.00 \\
\hline Maternal education level $\geq 12$ years & $0.93(0.88-0.99)$ & $0.66(0.54-0.80)$ \\
\hline Maternal age $<18$ years & $1.30(1.17-1.44)$ & $1.01(0.66-1.55)$ \\
\hline Maternal age $18-35$ years & 1.00 & 1.00 \\
\hline Maternal age $>35$ years & $1.66(1.54-1.80)$ & $1.36(1.08-1.71)$ \\
\hline
\end{tabular}

${ }^{a}$ Model included all maternal sociodemographic factors and pregnancy and labor complications examined in this study, including marital status, maternal age, prenatal smoking, number of fetuses born, maternal educational level, maternal race, previous preterm and small for gestational age births, uterine bleeding, eclampsia, preeclampsia, placenta previa, placental abruption, chronic hypertension, insulin-dependent diabetes and other forms of diabetes, acute/chronic lung disease, genital herpes, hydramnios/oligohydramnios, renal disease, and anemia. Only those variables with significant findings in our analysis are presented in this table.

${ }^{\mathrm{b}} \mathrm{OR}=$ odd ratios, $95 \% \mathrm{CI}=95 \%$ confidence intervals.

for insulin-dependent diabetes. The most elevated risk factor for stillbirth in current singleton pregnancies was uterine bleeding, which was associated with almost 6-fold increased odds $(\mathrm{AOR}=5.89,95 \% \mathrm{CI}=5.13-6.76)$. In twin pregnancies, it was the condition hydramnios/oligohydramnios $(\mathrm{AOR}=$ $4.72,95 \% \mathrm{CI}=3.70-6.02$ ). Black mothers were at least $50 \%$ more likely to experience stillbirth as compared to whites $(\mathrm{AOR}=2.10,95 \% \mathrm{CI}=1.99-2.22)$ in singletons and $(\mathrm{AOR}=$ $1.51,95 \% \mathrm{CI}=1.27-1.79)$ in twins. Additionally, there was an elevated risk of stillbirth in women of both advanced age (>35 years, $\mathrm{AOR}=1.66,95 \% \mathrm{CI}=1.54-1.80$ in singletons and AOR $=1.36,95 \% \mathrm{CI}=1.08-1.71$ in twins $)$ and adolescent age $(<18$ years, $\mathrm{AOR}=1.30, \mathrm{CI}=1.17-1.44$ in singletons). Nonsmokers have reduced odds of stillbirth in singletons $(\mathrm{AOR}=0.64$, $\mathrm{CI}=0.61-0.68)$ and no statistically significant difference in odds for stillbirth is found among twins pregnancies. Having at least 12 years of education is associated with reduced odds of stillbirth among both singletons $(\mathrm{AOR}=0.93,95 \% \mathrm{CI}=$ $0.88-0.99)$ and twins $(\mathrm{AOR}=0.66, \mathrm{CI}=0.54-0.80)$.

\section{Discussion}

An important finding in our study was that women whose previous infant was born preterm had an increased risk of stillbirth in their subsequent pregnancy. To our knowledge, this is the first time such a finding is reported in the US among twin pregnancies. And for singletons, this is the first time a large population data is used. This corroborates previous findings in Scotland and Sweden, which have shown that women whose previous infant was born at preterm and was small for gestational age had a higher risk of stillbirth in their second pregnancy $[23,25]$. Environmental or genetic factors that play a role in the progression of intrauterine asphyxia and fetal growth retardation could actually result in a higher risk of having infants that are small for gestational age and could also explain the relationship between the risk of having stillbirth and the delivery of a previous small for gestational age infant in subsequent pregnancies [23].

Our study reinforces previous research findings that repeatedly highlight the influence of multiple maternal sociodemographic factors on birth outcomes, such as stillbirth. As with our study, previous studies have shown that stillbirth rates are higher at the extremes of maternal age (i.e., young $[<18$ years] and advanced maternal age [ $>35$ years]) $[4,5]$. Similar to previous research $[4,6]$, our analysis revealed racial disparities in the rate of stillbirth, as black mothers experienced around twofold higher odds of stillbirth compared to white mothers. We also observed a decreased risk 
of stillbirth occurrence among mothers who did not smoke while pregnant, compared to those who did, providing further support for maternal smoking as an important risk factor for both antepartum and intrapartum stillbirth $[12,23,26]$.

This study has some limitations. There is the possibility of underreporting of medical risk factors and labor complications in the birth certificate data used as well as recall bias of certain exposures, such as prenatal smoking [27, 28]. Additionally, maternal self-report of smoking instead of the use of indicators for exposure, such as biomarkers, could be subject to errors generated from misclassification as a result of the chances of underreporting [26]. Although our findings provided further evidence that various pregnancy and labor conditions are associated with stillbirth, including eclampsia, placenta abruption, hypertension, diabetes, and multiple gestations $[10,14,28-30]$, genetic factors, which are known to affect the stillbirth occurrence [31], were absent in the data and could not be examined. As the study covers a nine-year period (1989-1997), it is possible that infants and women in the study population could have been subject to different obstetric procedures and practices that could have impacted fetoinfant morbidity and mortality outcomes. Additionally, unlike the Swedish and Scotland studies, our dataset lacks information on previous pregnancy SGA information.

Despite these limitations, our study has some key strengths. The population-based nature of the data used in analysis decreases the potential for our results to be affected by selection bias, making our findings more generalizable. Additionally, the reliability of the Missouri maternally linked cohort data files used in this study is well-documented, as it has been recognized as the "gold standard" in various validation studies of national datasets in the United States that require linking and matching procedures $[32,33]$.

In conclusion, stillbirth is a critical public health issue. While the etiology is not well understood, substantial medical risk factors and labor complications have been associated with stillbirth. This study builds on the existing public health knowledge regarding stillbirth with strong evidence that prior preterm birth and SGA play an important role in its occurrence. The findings may aid in the elucidation of the causal pathway between prior childbirth experiences and subsequent birth outcomes, such as stillbirth. Furthermore, our study underscores the importance of interconception care as a vital part of the comprehensive strategy to improve fetoinfant outcomes [34]. Targeted medical and obstetric care that takes into account a woman's childbirth history has the potential to reduce stillbirth occurrence and increase the likelihood of fetoinfant survival.

\section{Conflict of Interests}

The authors attest that there are no financial interests, commercial affiliations, or possible conflict of interests involved.

\section{References}

[1] M. F. MacDorman, D. L. Hoyert, J. A. Martin, M. L. Munson, and B. E. Hamilton, "Fetal and perinatal mortality, United States, 2003," National Vital Statistics Reports, vol. 55, no. 6, pp. 1-18, 2007.
[2] World Health Organization, Neonatal and Perinatal Mortality. Country, Regional and Global Estimates, World Health Organization, Geneva, Switzerland, 2006.

[3] R. M. Silver, M. W. Varner, U. Reddy et al., "Work-up of stillbirth: a review of the evidence," American Journal of Obstetrics and Gynecology, vol. 196, no. 5, pp. 433-444, 2007.

[4] U. M. Reddy, C.-W. Ko, and M. Willinger, "Maternal age and the risk of stillbirth throughout pregnancy in the United States," The American Journal of Obstetrics and Gynecology, vol. 195, no. 3, pp. 764-770, 2006.

[5] C. V. Ananth, S. Liu, W. L. Kinzler, and M. S. Kramer, "Stillbirths in the United States, 1981-2000: An age, period, and cohort analysis," American Journal of Public Health, vol. 95, no. 12, pp. 2213-2217, 2005.

[6] H. M. Salihu, B. A. Kinniburgh, M. H. Aliyu, R. S. Kirby, and G. R. Alexander, "Racial disparity in stillbirth among singleton, twin, and triplet gestations in the United States," Obstetrics \& Gynecology, vol. 104, no. 4, pp. 734-740, 2004.

[7] M. Willinger, C.-W. Ko, and U. M. Reddy, "Racial disparities in stillbirth risk across gestation in the United States," American Journal of Obstetrics and Gynecology, vol. 201, no. 5, pp. 469.el469.e8, 2009.

[8] NIH, Placental, Pregnancy Conditions Account for Most Stillbirths, 2011.

[9] D. Y. Huang, R. H. Usher, M. S. Kramer, H. Yang, L. Morin, and R. C. Fretts, "Determinants of unexplained antepartum fetal deaths," Obstetrics and Gynecology, vol. 95, no. 2, pp. 215-221, 2000.

[10] A. Conde-Agudelo, J. M. Belizán, and J. L. Díaz-Rossello, "Epidemiology of fetal death in Latin America," Acta Obstetricia et Gynecologica Scandinavica, vol. 79, no. 5, pp. 371-378, 2000.

[11] G. R. Del Rosario, T. Lewis, B. Irons, S. Campbell-Forrester, H. L. Weiss, and P. E. Jolly, "Assessment of risk factors for stillbirth among pregnant women in Jamaica," Journal of Obstetrics and Gynaecology, vol. 24, no. 7, pp. 750-755, 2004.

[12] T. C. Marufu, A. Ahankari, T. Coleman, and S. Lewis, "Maternal smoking and the risk of still birth: systematic review and metaanalysis," BMC Public Health, vol. 15, article 239, 2015.

[13] K. Lamont, N. W. Scott, G. T. Jones, and S. Bhattacharya, "Risk of recurrent stillbirth: systematic review and meta-analysis," The British Medical Journal, vol. 350, Article ID h3080, 2015.

[14] G. R. Gutiérrez, M. C. A. Ceja, P. A. L. Ponce de León, and A. E. Olvira, "Risk factors of stillbirth," Ginecologia y Obstetricia de Mexico, vol. 72, pp. 109-115, 2004.

[15] E. M. McClure, M. Nalubamba-Phiri, and R. L. Goldenberg, "Stillbirth in developing countries," International Journal of Gynecology and Obstetrics, vol. 94, no. 2, pp. 82-90, 2006.

[16] J. E. Lawn, M. Yakoob, R. A. Haws, T. Soomro, G. L. Darmstadt, and Z. A. Bhutta, "3.2 million stillbirths: epidemiology and overview of the evidence review," BMC Pregnancy and Childbirth, vol. 9, supplement 1, article S2, 2009.

[17] A. H. Baqui, Y. Choi, E. K. Williams et al., "Levels, timing, and etiology of stillbirths in Sylhet district of Bangladesh," BMC Pregnancy and Childbirth, vol. 11, article 25, 34 pages, 2011.

[18] G. C. S. Smith, "Life-table analysis of the risk of perinatal death at term and post term in singleton pregnancies," The American Journal of Obstetrics and Gynecology, vol. 184, no. 3, pp. 489496, 2001.

[19] H. Yuan, R. W. Platt, L. Morin, K. S. Joseph, and M. S. Kramer, "Fetal deaths in the United States, 1997 vs 1991," American Journal of Obstetrics \& Gynecology, vol. 193, no. 2, pp. 489-495, 2005. 
[20] J. E. Lawn, M. G. Gravett, T. M. Nunes, C. E. Rubens, C. Stanton, and The GAPPS Review Group, "Global report on preterm birth and stillbirth (1 of 7): definitions, description of the burden and opportunities to improve data," BMC Pregnancy and Childbirth, vol. 10, supplement 1, article S1, 2010.

[21] D. H. Thom, L. M. Nelson, and T. L. Vaughan, "Spontaneous abortion and subsequent adverse birth outcomes," The American Journal of Obstetrics and Gynecology, vol. 166, no. 1, pp. 111116, 1992.

[22] K. S. Joseph, K. Demissie, and M. S. Kramer, "Obstetric intervention, stillbirth, and preterm birth," Seminars in Perinatology, vol. 26, no. 4, pp. 250-259, 2002.

[23] P. J. Surkan, O. Stephansson, P. W. Dickman, and S. Cnattingius, "Previous preterm and small for gestational age births and the subsequent risk of stillbirth," The New England Journal of Medicine, vol. 350, no. 8, pp. 777-785, 2004.

[24] U. M. Reddy, S. K. Laughon, L. Sun, J. Troendle, M. Willinger, and J. Zhang, "Prepregnancy risk factors for antepartum stillbirth in the United States," Obstetrics \& Gynecology, vol. 116, no. 5, pp. 1119-1126, 2010.

[25] G. C. S. Smith, I. Shah, I. R. White, J. P. Pell, and R. Dobbie, "Previous preeclampsia, preterm delivery, and delivery of a small for gestational age infant and the risk of unexplained stillbirth in the second pregnancy: a retrospective cohort study, Scotland, 1992-2001," American Journal of Epidemiology, vol. 165, no. 2, pp. 194-202, 2007.

[26] M. H. Aliyu, H. M. Salihu, R. E. Wilson, and R. S. Kirby, "Prenatal smoking and risk of intrapartum stillbirth," Archives of Environmental and Occupational Health, vol. 62, no. 2, pp. 8792, 2007.

[27] C. V. Ananth, "Perinatal epidemiologic research with vital statistics data: validity is the essential quality," The American Journal of Obstetrics and Gynecology, vol. 193, no. 1, pp. 5-6, 2005.

[28] D. Getahun, C. V. Ananth, and W. L. Kinzler, "Risk factors for antepartum and intrapartum stillbirth: a population-based study," The American Journal of Obstetrics and Gynecology, vol. 196, no. 6, pp. 499-507, 2007.

[29] L. L. Simpson, "Maternal medical disease: risk of antepartum fetal death," Seminars in Perinatology, vol. 26, no. 1, pp. 42-50, 2002.

[30] A. W. Eriksson and J. Fellman, "Factors influencing the stillbirth rates in single and multiple births in Sweden, 1869 to 1967," Twin Research and Human Genetics, vol. 9, no. 4, pp. 591-596, 2006.

[31] R. J. Wapner and D. Lewis, "Genetics and metabolic causes of stillbirth," Seminars in Perinatology, vol. 26, no. 1, pp. 70-74, 2002.

[32] J. Martin, S. Curtin, M. Saulnier, and J. Mousavi, Development of the Matched Multiple Birth File, 1995-1998 Matched Multiple Birth Dataset, National Center for Health Statistics, Hyattsville, Md, USA, 2003.

[33] H. M. Salihu, O. Lynch, A. P. Alio, and J. Liu, "Obesity subtypes and risk of spontaneous versus medically indicated preterm births in singletons and twins," American Journal of Epidemiology, vol. 168, no. 1, pp. 13-20, 2008.

[34] K. Johnson, S. F. Posner, J. Biermann et al., "Recommendations to improve preconception health and health care-United States. A report of the CDC/ATSDR Preconception Care Work Group and the Select Panel on Preconception Care," MMWR Recommendations and Reports, vol. 55, no. 6, pp. 1-23, 2006. 


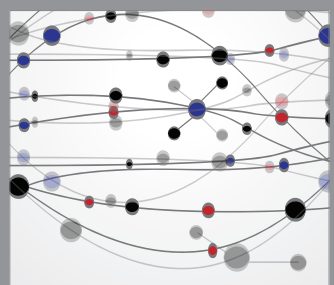

The Scientific World Journal
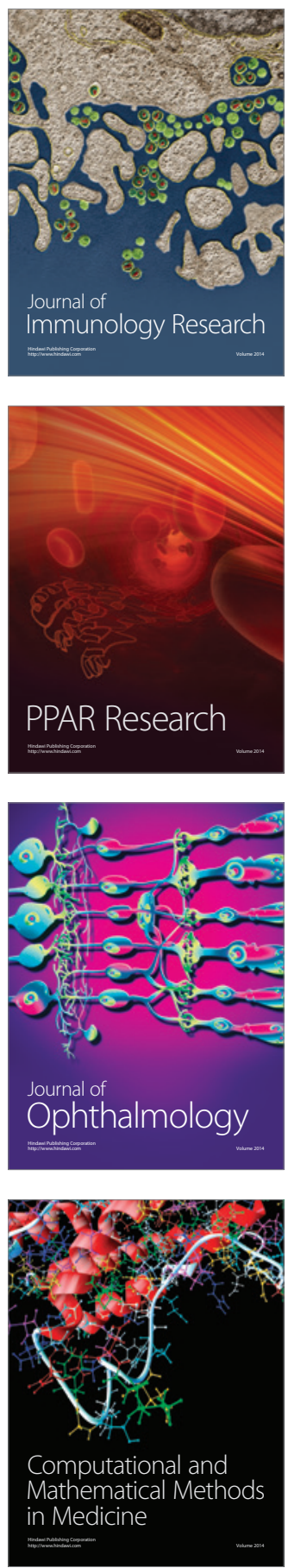

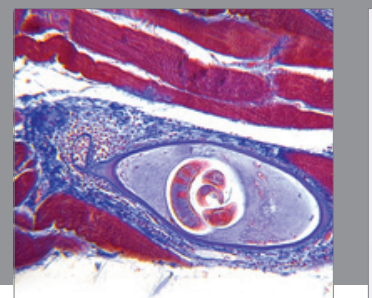

Gastroenterology

Research and Practice
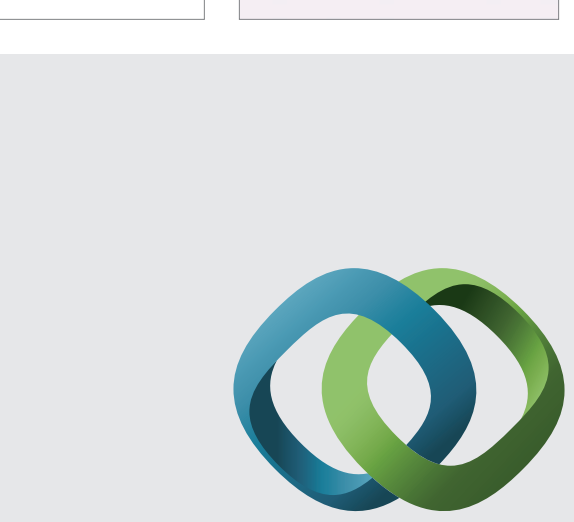

\section{Hindawi}

Submit your manuscripts at

http://www.hindawi.com
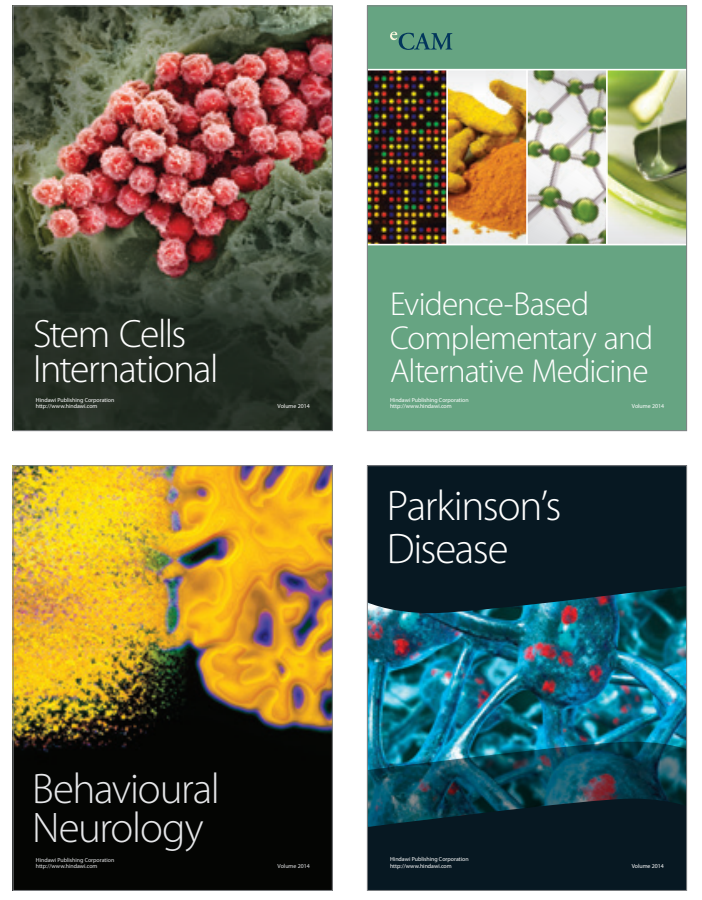
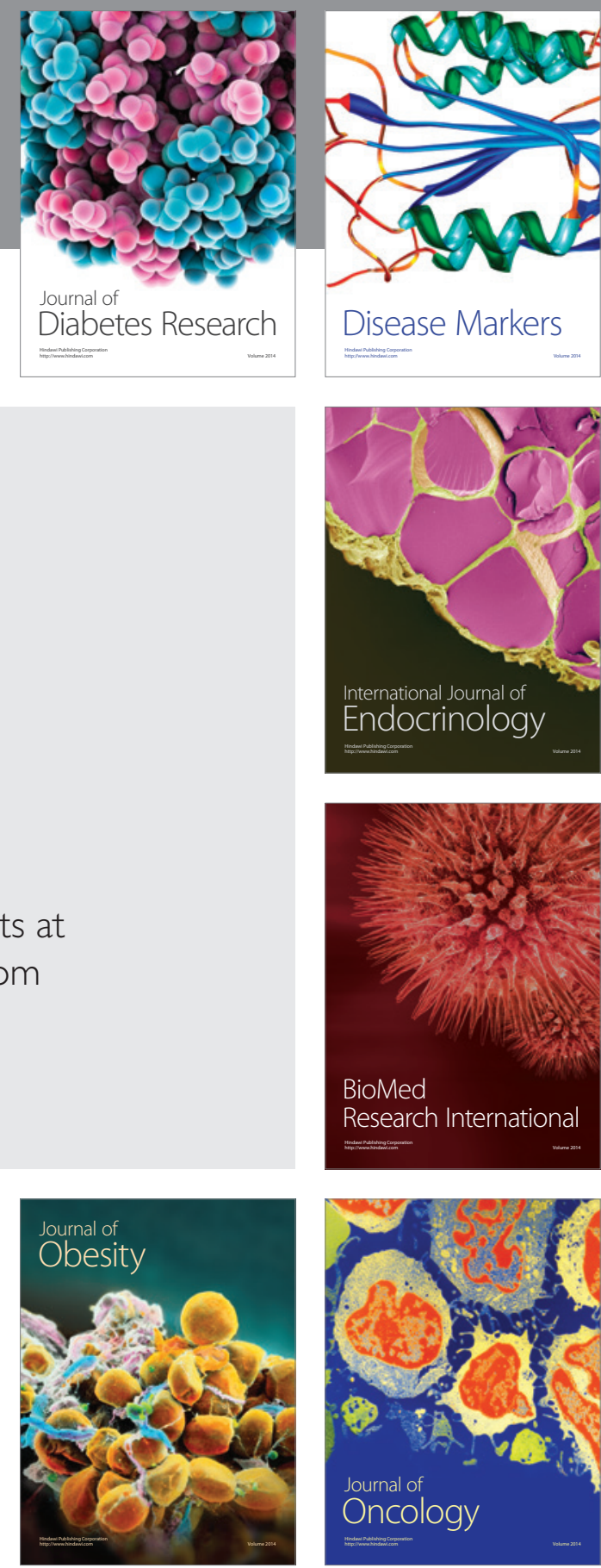

Disease Markers
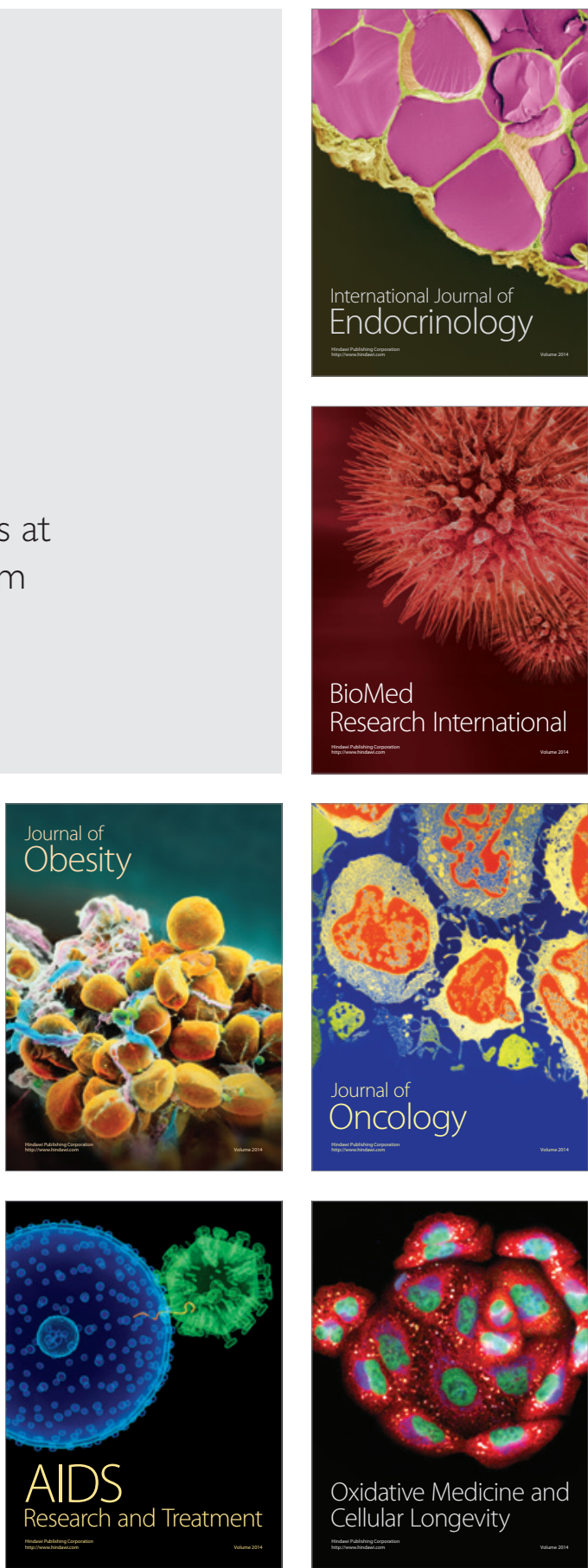